\title{
Nihilismo y metafísica en Danilo Cruz Vélez
}

\author{
Nihilismo y metafísica en Danilo Cruz Vélez
}

Niilismo e metafísica em Danilo Cruz Vélez

Fecha de entrega: 15 de diciembre de 2013

Fecha de evaluación: 15 de abril de 2014

Fecha de aprobación: 15 de junio de 2014

Veyer Mendoza Sandoval*

\section{Resumen}

El propósito de este escrito es estudiar las investigaciones de Danilo Cruz Vélez sobre el nihilismo nietzscheano en relación con la metafísica. Para la consecución de este objetivo, se requieren parámetros para la comparación entre los trabajos y escritos del pensador colombiano con los estudios e investigaciones de Martin Heidegger, con el fin de establecer los nexos e influencias del pensador alemán en nuestro eximio filósofo colombiano. Lo anterior nos permite concluir, con la autoridad y el rigor de los textos mismos, que las tesis de Cruz Vélez a este respecto no son más que la traducción del alemán al español de los estudios de Heidegger sobre Nietzsche, cosa que se produce como consecuencia de los seminarios impartidos por Heidegger en

* Magíster en Filosofía latinoamericana de la Universidad Santo Tomás, especialista en Filosofía Colombiana de la misma universidad, licenciado en Filosofía de la Universidad de San Buenaventura. Docente de los Liceos del Ejército. Correo electrónico: veyercito@yahoo.com 
la universidad de Friburgo, a los cuales asistió Danilo Cruz Vélez en calidad de estudiante.

Palabras clave: nihilismo, metafísica, ontología, teleología, inmoralismo.

\section{Abstract}

The purpose of this writing, is to study around Danilo Cruz Vélez research on a topic ofuniversal philosophy, as in the Nietzschean nihilism in relation to metaphysics. In pursuit of this objective, is the need for parameters of comparison between the work and writings of the Colombian thinker, with studies and research of Martin Heidegger, in order to Estbaliz the relationship an influences of German thinker, in our distinguished Colombian philosopher. This allows us to concluye with authority and accuracy of the texts themselves, that Vélez Cruz thesis in this respect are nothing but the translation from German to Spanish, from Studies of Heideger'sNietasche, as a resulto of the seminars given by Heidegger at the University of Freiburg, wich Danilo Cruz Vélezatended as a student.

Keywords: Nihilism, metaphysics, ontology, teleology, immorality.

\section{Resumo}

O propósito deste trabalho é estudar as investigações de Danilo Cruz Vélez sobre o niilismo de Nietzsche em relação à metafísica. Para atingir este objetivo requerem-se parâmetros para a comparação entre os trabalhos e os escritos do pensador colombiano com os estudos e investigações de Martin Heidegger, a fim de estabelecer as ligações e influências do pensador alemão em nosso exímio filósofo colombiano. Isso mesmo permite-nos concluir, com a autoridade e o rigor dos textos mesmos, que a tese de Cruz Vélez a este respeito não e nada mais do que a tradução do alemão para o espanhol dos estudos de Heidegger sobre Nietzsche, questão que ocorre como resultado dos seminários ministrados por Heidegger na Universidade de Friburgo, aos quais Danilo Cruz Vélez assistiu como aluno.

Palavras-chave: niilismo, metafísica, ontologia, teleologia, imoralismo. 


\section{Introducción}

Después de haber hecho un seguimiento a la obra de Cruz Vélez, tratando de ubicar los textos que nos llevarán al tema del nihilismo, se encontró un primer artículo publicado por la editorial Norma en sus colecciones Cara y Cruz, titulado "El puesto de Nietzsche en la historia de la filosofía". En este se concibe al nihilismo como un elemento inherente a la metafísica a la vez que se aborda el tema exclusivamente en relación con Nietzsche. Esto reviste especial importancia, dado que tiene que ver directamente con el problema planteado para este escrito. De este documento, se extraen 12 citas y, aparte de esto, se introduce una cita de un artículo titulado "Nihilismo e inmoralismo", publicado en la revista Eco.

A la hora de relacionar al pensador colombiano con Heidegger, se ve la necesidad detrabajar con los dos tomos de Heidegger sobre Nietzsche y un aparte del tomo I, titulado "La voluntad de poder como arte", publicado en Nietzsche: 125 años, por la editorial Temis de Bogotá en 1977. A partir de los tomos de Heidegger se introducen 14 citas, mientras que del último texto mencionado se extraen siete, para un total de 34 citas primarias en este trabajo.

El propósito de este capítulo es analizar el trabajo sobre nihilismo y metafísica realizado por Danilo Cruz Vélez. Para la consecución de este objetivo nos encontramos con situaciones que nos obligan a abordar a Nietzsche y Heidegger. Nietzsche entra en el panorama de este escrito, en la medida que el tema en cuestión lo aborda el pensador colombiano a partir de Nietzsche. No obstante lo anterior, no se introduce ninguna cita del filósofo alemán, puesto que esto podría desviar los objetivos de esta investigación. Se ve la necesidad de hacer referencia a Martin Heidegger, en cuanto que se observa la influencia directa en los trabajos del profesor Danilo Cruz Vélez, y esto, a diferencia de lo anterior, exige citar con el fin de fijar algunos parámetros de comparación.

En su estructura, se ve la necesidad de distribuir el capítulo en seis secciones. La primera es una introducción, cuyo propósito es orientar y facilitar la lectura, de modo que de antemano se dé a conocer los temas abordados, los textos, el orden y la estructura misma del escrito.

En un segundo momento, se hará un resumen del texto de Danilo Cruz Vélez, en el que se aborda el tema de estudio de manera explícita. A partir de este trabajo se 
desprenden las cuatro secciones que restan, a saber "Nietzsche dentro del horizonte de la metafísica", "Parámetros de comparación entre Danilo Cruz Vélez y Martin Heidegger en torno a la metafísica de Nietzsche", "Nihilismo como fin de la metafísica" y, por último, "Nietzsche y la metafísica de la subjetividad".

\section{Análisis general del texto de Danilo Cruz Vélez sobre nihilismo y metafísica}

En esta sección, se pretende dar cuenta de la lectura e interpretación del texto de Danilo Cruz Vélez "El puesto de Nietzsche en la historia de la filosofía", en el que el pensador colombiano aborda el tema del nihilismo en relación con la metafísica.

Se puede decir, en principio, que el texto de Danilo Cruz Vélez es un ensayo de 50 páginas, que pretende dar cuenta del lugar ocupado por Nietzsche dentro de la historia de la filosofía. Tratando de dar una identidad temática a la obra de Nietzsche, una primera tesis lanzada por el profesor colombiano es justamente es acerca de la necesidad de ver a Nietzsche dentro del horizonte de la metafísica (cf. Cruz Vélez, 1997, p. 15). Tanto es así que la filosofía de Nietzsche es una crítica restrictiva contra toda la metafísica de Occidente. Según el filósofo alemán, Platón es el fundador de la tradición metafísica, la cual se ha perpetuado hasta Hegel, quien la lleva a su máxima expresión. Por esto, la filosofía de Nietzsche se puede definir como un platonismo al revés. A la hora de resolver la pregunta fundamental de la metafísica “ ¿qué es lo ente, lo que es, en cuanto tal?", lo primero que trata de desvirtuar Nietzsche es la teoría de los dos mundos de Platón. En esta teoría, se hace una escisión de la realidad y se crean los conceptos de mundo sensible o physis y mundo de las ideas o eidos. Esto se da dentro de unas categorías que dan lugar a una diferenciación de rango ontológico, en la que el mundo de las ideas, por ser lo fundante, lo en sí, ocupa un lugar preponderante, mientras el mundo sensible,por ser una especie de copia desteñida del mundo de las ideas, ocupa un segundo lugar. El trabajo de Nietzsche es el de restituirle al mundo de la physis su importancia, y, para esto, su esfuerzo está encaminado a negar la posibilidad de un mundo suprasensible. Para la consecución de este propósito, como quedó consignado líneas atrás, realiza un capítulo de El Crepúsculo de los ídolos. En este, Nietzsche hace una historia a través de seis momentos y señala la manera como el platonismo se ha filtrado en cada uno de estos, hasta que finalmente, en el sexto momento, Zaratustra tiene su incursión en esta historia y logra desvirtuar la idea del mundo verdadero, es decir el eidos platónico (29, 30, 31). 
Con vistas de superar la idea de un supuesto mundo verdadero platónico, asegura Cruz Vélez, aparece el nihilismo, el cual es definido por Nietzsche como el proceso mediante el cual los valores supremos han perdido su valor. Los valores supremos eran esas instancias trascendentes derivadas del mundo de las ideas de Platón. Al desvirtuarse, se llega también a postular la muerte de Dios. Este reclamo no se refiere de manera expresa al dios del cristianismo, sino a todos los fundamentos suprasensibles dados a través de la historia de la metafísica a partir de Platón (cf. 32, 33).

Es por lo anterior que Danilo Cruz Vélez considera que el fin de la metafísica, la volatilización del mundo verdadero y la muerte de Dios equivalen igualmente al nihilismo, visto desde diferentes perspectivas.

Una vez superada la idea de un mundo verdadero, la tarea de Nietzsche, a juicio de Cruz Vélez, es la de instalarse en el mundo sensible. Para esto, se debe superar todos los vestigios que han quedado de la idea del mundo suprasensible. En este caso, los escombros y vestigios hacen referencia al lenguaje o a conceptos metafísicos con los que venía operando el platonismo. Por esta razón, Nietzsche emprende una crítica a la metafísica a través de un análisis psicológico del lenguaje (Cruz Vélez, 1972, pp. 37-39).

Por medio del análisis psicológico, Nietzsche reduce el mundo suprasensible y los conceptos metafísicos a la fuente de donde brotan, que en este caso es la vida humana, la cual se caracteriza por un odio contra la vida natural, lo real o el mundo de la physis. El "mundo verdadero" como primera perspectiva y Dios como fundamento último definen el contexto desde el cual la razón responde en la metafísica tradicional a la pregunta por el ser del ente y desde la cual se acuña la falsificación del mundo verdadero. Por lo tanto, es la razón y el intelecto, y no la sensibilidad, los que engañan, a diferencia de lo que propone Platón.

Si el antecesor de Platón es Parménides, Heráclito es considerado por Nietzsche como su antecedente más próximo. Parménides, a diferencia de los demás filósofos presocráticos, se sale del mundo de la physis y se inventa el mundo de la razón. De esta forma, comienza el dualismo cosmológico que a la postre da lugar a la doctrina de los dos mundos platónica, que sirve de fundamento a toda la metafísica de occidente. Nietzsche, al asumir en su filosofía el mundo del devenir o de la physis de Heráclito, considera estar por fuera de la metafísica y muere con la convicción de haber realizado una crítica a la metafísica allende a esta. En este sentido, Danilo Cruz Vélez va más allá de la exégesis y presenta su tesis, según la cual, si queremos 
encontrar el puesto de Nietzsche dentro de la historia de la filosofía, debemos ubicarlo dentro de la metafísica de la subjetividad. El primer argumento utilizado por Cruz Vélez se propone demostrar que Nietzsche se formulóla pregunta fundamental de la metafísica a saber: “iqué es lo ente en cuanto tal?” (cf. Cruz Vélez, 1997, p. 47). A esto responde: el mundo. Esta respuesta da lugar a la pregunta “¿qué es el mundo en cuanto tal?". A la hora de responder, no se sale del mundo hacia un trasmundo, por el contrario, le restituye el poder al mundo natural, a lo sensible, al mundo de la physis.

Esta última respuesta da lugar a una nueva pregunta "¿qué es el mundo de la physis?".A lo que responde que el mundo es vida (leben) y con esto toma distancia de los griegos clásicos, puesto que el ser ni es estático e inmutable como en Parménides, pero tampoco está en devenir en el sentido de Heráclito. El del mundo es un devenir que bien se puede equiparar con la vida, el querer y el actuar, y la vida no es solo la vida orgánica de las plantas y los animales, sino que es el ser, es decir, la totalidad de los entes.

Cuando el concepto de vida adquiere en Nietzsche una connotación de orden ontológico, con la cual pretende superar el conceptoque se asume en la biología por Spencer, en el que se definía la vida como adaptación, o en la de Darwin, quien la define como conservación. A partir de Nietzsche, la vida entra a ser concebida en términos metafísicos como voluntad de poder. La voluntad y el querer hacen referencia a un ego volo y este a un ego cogito. Por esta razón,la filosofía de Nietzsche se circunscribe en la metafísica de la subjetividad de tendencia cartesiana y moderna. No obstante, la metafísica de Nietzsche no habla de representación sino de voluntad de poder, quizá sea esto lo que lo diferencia de la filosofía moderna.

Al igual que en la Modernidad, Nietzsche ve en el hombre como sujeto, el fundamento explicativo del mundo. Pero la visión antropológica de Nietzsche, a pesar de moverse dentro del contexto del animal rationale, difiere de la propuesta moderna y de la tradición en general, si se tiene en cuenta que esta le da un lugar especial a lo animalitas como elemento propio del mundo sensible, en detrimento de la ratio que representa el mundo inteligible. Por otro lado, y teniendo en cuenta lo anterior, el hombre no es el“yo pienso" cartesiano, sino el sujeto de los apetitos, las pasiones, los instintos e impulsos; este sujeto lo denomina Nietzsche con el término alemán Leib. Este término no tiene una traducción literal en español, pero Cruz Vélez, apelando a sus conocimientos de la lengua alemana, lo define como un cuerpo con interioridad, una especie de intracuerpo, cuerpo vivido desde adentro o, en últimas, un yo 
corporal, y en este sentido no es un yo racional, sino un elemento que se circunscribe al mundo de la physis.

Si bien es cierto que Nietzsche no define al hombre como un elemento constitutivo de la esenciadel ser del mundo, sí lo ve como parte del mundo, y, por tanto, es como un espejo de este. De este modo, al tener una mirada introspectiva del hombre,podemos acercarnos a lo que es el mundo. Es así como el sujeto en esencia es un querer crecer incesante, movido por los apetitos, las pasiones y los instintos, es decir, el hombre es voluntad de poder, y si el hombre es vibración del mundo, este último, se infiere, ha de ser también voluntad de poder.

En últimas, concluye Danilo Cruz Vélez, Nietzsche no logra superar la metafísica tradicional allende a la metafísica misma, sino que su crítica se hace desde el seno de la metafísica de la subjetividad. A parte de lo anterior, Nietzsche a la hora de profundizar el concepto de ser del mundo manejado por el filósofo alemán, como eterno retorno de lo mismo, está circunscrito a las condiciones del ser de la tradición dadas por Parménides y Platón, que lo entendían como un serestático, inmóvil e inmutable en contra del devenir que tanto defendió.

\section{Nietzsche dentro del horizonte de la metafísica}

Para Cruz Vélez, el suelo sobre el que se mueve toda la filosofía de Nietzsche es en el de una crítica de la metafísica de occidente. Dicha metafísica, asegura el mismo filósofo, hunde sus raíces en Platón, de ahí que con la expresión platonismo, Nietzsche hace referencia a toda la metafísica de occidente, desde Platón hasta Hegel, quien a juicio del mismo autor, es quien la lleva a su máxima expresión.

Para justificar lo anterior, Cruz Vélez trae a colación una frase de Nietzsche del invierno de 1870-1871cuando el filosofo contaba con 26 años y que fue recogida por los estudios de Alfred Baeumleren la que afirma "mi filosofía es un platonismo al revés" (Cruz Velez, 1997, p. 18).

En estas circunstancias, la frase, según Cruz Vélez, es la intuición fundamental de Nietzsche, o si se quiere, mejor, una "premonición”con la que vaticina toda su obra.

Esta frase se convierte en la "declaración de guerra" que hace Nietzsche a la metafísica o, mejor, a la metafísica de Occidente, vale la pena aclarar, dado quecomo se 
dijo al cierre de la unidad anterior, no obstante de que Nietzsche pretenda con su filosofía superar la metafísica, allende a la metafísica misma, termina realizando una crítica a una región de la metafísica desde el seno de esta. Quizás sea esta una de las tesis más importantes de Danilo Cruz Vélez a este respecto, pues lo aleja de la mera interpretación o exégesis de los textos de Nietzsche, para colocarlo en un plano más argumentativo y propositivo.Por esta razón, en esta unidad, se tratará demostrar el desarrollo de la discusión que emprendió Cruz Vélez con Nietzsche con el propósito de decir que, pese a su esfuerzo, Nietzsche nunca pudo sustraerse de la metafísica.

Danilo Cruz Vélez no desconoce que el término metafísica se introduce por primera vez en el trabajo de clasificación de la obras de Aristóteles que realizara Andrónico de Rodas. No obstante, segúnCruz Vélez, en sentido estricto, lametafísica precede ese momento e incluso, a juzgar por su etimología, se puede afirmar que el término aparece con Platón. Se sabe que la filosofía surge con la pregunta por el ser del ente, es decir, por la estructura común de todos los seres, de cuya unidad debía surgir la multiplicidad de seres que se constatan en la realidad. La multiplicidad en cuanto totalidad de cosas es entendida dentro del contexto del mundo griego como physis. A la hora de responder esa pregunta, Platón introdujo un elemento que trasciende y se sustrae de la physis (ya que está más allá): este fue el concepto de idea; de ahí que esa disciplina sea meta-physis y se denomine metafísica.

Con la propuesta de Platón, se introduce otro mundo, se produce la escisión de la realidad, esto es, una diferencia de rango antológico entre dos dimensiones. En esta distinción, el eidos al operar como elemento fundantees visto como lo esencial, lo en sí, lo verdadero, lo auténtico; mientras que la physis en cuanto elemento fundado es solo una copia "desteñida" de la verdad, un reflejo del eidos fundador, una mera participación del único ser.

Se puede ver cómo la respuesta a una pregunta de carácter metafísico dió lugar a la teoría de los dos mundos en Platón. Esta, a su vez, se conviertió en el soporte de toda la metafísica de occidente, dado que a pesar de las modificaciones en las diferentes etapas, siempre se puede evidenciar estedualismo.

De ser estas tesis el producto de las investigaciones de Danilo Cruz Vélez, no habría duda de que se estáfrente a un filósofo auténtico, en la medida en que su trabajo logra superar la mera exégesis, para reflexionar e interpretar, con un sello propio, temas filosóficos de carácter universal; no obstante, al confrontar los estudios del 
profesor colombiano con los trabajos de Heidegger sobre Nietzsche, se encuentra que muchas de las tesis fundamentales de Danilo Cruz Vélez acerca del nihilismo y de la metafísica "coincidencialmente" son las mismas de Heidegger. Por esto, a continuación, se apelará a los mismos textos para confrontar y corroborarlo expuesto anteriormente.

La mayor parte de los estudios de Heidegger sobre Nietzsche están publicados en dos tomos, traducidos al español por Juan Luis Vermal, y que salieron al mercado gracias a Ediciones Destino de Barcelona. Tal como lo expresa el traductor, estos tomos son la compilación de las lecciones dictadas por Heidegger en la Universidad de Friburgo, entre los años que van de 1936 a 1940.También incluyen otros trabajos inéditos no publicados hasta entonces, así como material que resultó de investigaciones realizadas de 1940 a 1946, por el mismo filósofo. El primer tomo está dividido en tres partes, y la primera parte, a su vez, consta de 25 subcapítulos. No obstante que el propósito fundamental de Heidegger en la parte uno del tomo primero sea la de hacer una reconstrucción fenomenológica que permita presentar la voluntad de poder como arte, en el subcapítulo 20 que lleva por título "La verdad en el platonismo y en el positivismo" se pueden encontrar las siguientes tesis, que coinciden de manera clara con las de Cruz Vélez:

Invertir el platonismo quiere decir, entonces: invertir los criterios de medida; por decirlo así, lo que en el platonismo estaba debajo y tenía que medirse por lo suprasensible tiene que pasar arriba y lo suprasensible tiene que ponerse a su servicio. Al llevar a cabo la inversión, lo sensible se convierte en lo propiamente ente, es decir en lo verdadero, en la verdad. (Heidegger, 2000a, p. 151)

La anterior cita de Heidegger permite evidenciar que la tesis presentada por Cruz Vélez, según la cual toda la filosofía de Nietzsche es un platonismo al revés, de modo que el esfuerzo de Nietzsche es recuperar el valor del mundo sensible y dejar sin piso el mundo suprasensible de Platón, no es original, sino del filósofode la selva negra. Igualmente, se puedenencontrar en el subcapítulo "La inversión nietzscheana del platonismo" citas más explícitas al respecto como las siguientes: "La filosofía de Nietzsche es, según su propio testimonio, un platonismo invertido. Preguntamos: ¿en qué sentido se transforma, gracias a la inversión, la relación entre belleza y verdad características del platonismo?"(2000a, p. 190). 
Veamos otra cita al respecto:

¿Pero qué quiere decir: lo sensible está arriba? Que es lo verdadero, lo propiamente ente. Si se toma la inversión solo de esta manera, se mantienen, por así decirlo, los lugares vacíos de arriba y de abajo, solo que son ocupados de diferente manera. Pero en la medida en que este arriba o este abajo determinan la estructura del platonismo, este esencialmente se mantiene. La inversión no lleva a cabo aquello que tiene que llevar a cabo en cuanto superación del nihilismo: una superación del platonismo desde su base. (2000a, p. 190)

En el capítulo Vl del segundo tomo encontramos las siguientes citas: “[t]oda metafísica es platónica. El cristianismo y las formas de su secularización moderna son 'platonismo para el pueblo"' (Heidegger, 2000b, p.222). Veamos otra cita que corrobora la anterior: "[e]l pensamiento de Nietzsche, en conformidad con todo el pensamiento de occidente desde Platón, es metafísica” (2000b, p. 209).

Con las citas anteriores, se puede concluir, siguiendo al filósofo de la selva negra, que la filosofía de Nietzsche es un platonismo invertido, puesto que este equipara la metafísica de Occidente con el platonismo, más exactamente con la teoría de los dos mundos, que da lugar a una escisión de la realidad.En esta se hace una diferenciación en el rango ontológico, que favorece al mundo inteligible o suprasensible de Platón.Esto es lo que da lugar a la obra de Nietzsche, que se caracteriza justamente por realizar una inversión que permita superar el mundo de las ideas platónicas, que resultó ser una quimera, para, de esta forma, restituirle el valor al mundo natural o físico, que era considerado por Platón como una sombra del mundo de las ideas. Estas tesis son las mismas expuestas por Danilo Cruz Vélez y que se señalaron en las cinco primeras páginasde este capítulo.

A pesar de que estas tesis son presentadas por Heidegger en un contexto temático diferente al de Cruz Vélez, puesto que el primero quiere presentar la voluntad de poder como arte, y el profesor colombianopretendehacer una presentación de Nietzsche que le permita ubicarlo en el contexto general de la historia de la filosofía,las ideas y tesis presentadas son exactamente las mismas. Son innumerables las citas tomadas de los estudios de Heidegger sobre Nietzsche que corroboran la poca originalidad del profesor colombiano a la hora de realizar sus estudios en torno a Nietzsche, tanto es así que lo más práctico sería colocar un confróntese que remitiera a la primera 
parte del primer tomo de Heidegger en toda el texto de Cruz Vélez.Sin embargo, se seleccionarán los textos que resulten más explícitos a la hora de cumplir esta tarea.

En el capítulo "El nihilismo europeo" hayun subcapítuloque Heidegger tituló "La verdad en el platonismo y en el positivismo". Quizá sea este uno de los estudios de Heidegger, junto con un capítulo acerca del Crepúsculo de los ídolos, más explícitos a la hora de corroborar las tesis mencionadas por Danilo Cruz Vélez.

La cita del Crepúsculo de los ídolos, a la que se hizo referencia anteriormente, la retoma literalmenteel investigador colombiano ylogra aparentemente rastrear de manera magistral“el platonismo al revés” como define la filosofía de Nietzsche, así como su idea de que el platonismo es el soporte de toda la metafísica de occidente.Aunque asegura que esta idea está presente en toda la obra del pensador alemán, solo trae a colación el comentario que hace respecto a algunas citas claves de las últimas obras de Nietzsche, como El Crepúsculo de los ídolos y Los ditirambos dionisiacos. Esto es porque, según él, la sistematización de este trabajo amerita un nuevo estudio, con objetivos diferentes que no permiten polarizar los intereses y logros propuestos en este estudio.

La cita en mención hace parte de un capítulo que se titula "Cómo al fin 'el mundo verdadero' se convirtió en una fábula: historia de un error”.Por la importancia que representa en el trabajo, se transcribiráen su totalidad. En un primer lugar, se tomará la cita del texto de Cruz Vélez, con el fin de dar mayor precisión, puesto que, en este caso, lo que nos interesa en principio es exponer el trabajo del pensador colombiano en torno a Nietzsche, y, luego, se confrontará con las referencias de Heidegger. En segundo lugar, lo que se pretende es mostrar la influencia directa del pensador alemán en Cruz Vélez.

1. El mundo verdadero, accesible al sabio, al piadoso, al virtuoso - este vive en ese mundo, es ese mundo-. (La forma más antigua de la idea, relativamente sensata, convincente.Perífrasis de la frase: 'Yo, Platón, soy la verdad').

2. El mundo verdadero, inaccesible ahora, pero prometido al sabio, al piadoso, al virtuoso ('al pecador que hace penitencia'). (Progreso de la idea: se hace más matizada, más capciosa, más incomprensible — se convierte en mujer, se vuelve cristiana...-). 
3. El mundo verdadero, inaccesible, indemostrable, no se puede prometer, pero es ya un consuelo en cuanto meramente pensado, un deber, un imperativo. (En el fondo, el viejo sol, pero por entre niebla y escepticismo;la idea se ha hecho sublime, descolorida, nórdica, de Königsberg).

4. El mundo verdadero - ¿inaccesible? - En todo, caso, no alcanzado.Y, en cuanto no alcanzado, incognoscible. Por lo tanto, ni consolador, ni liberador, ni obligante: ¿a que nos puede obligar algo desconocido? (Comienza a amanecer. Primer despertar de la razón. Canto de gallo del positivismo.)

5. El mundo 'verdadero'-una idea que no sirve para nada que ni siquiera es obligante, - una idea estéril, que se ha hecho superflua, por lo tanto, una idea refutada: ¡Deshagámonos de ella! (Claro día; desayuno; retorno del bon sens y de la alegría; sonrojo de Platón gran algazara de todos los espíritus libres.)

6. Nos deshicimos del mundo verdadero. ¿Cuál nos queda? ¿Quizás el aparente? ¡No, no! ¡Con el mundo verdadero nos deshicimos también del mundo aparente! (Mediodía: momento de la sombra más corta: fin del más antiguo error; cumbre de la humanidad; incipitZaratustra). (Cruz Vélez, 1997, p. 26).

Como bien lo señala Cruz Vélez, este capítulo es una síntesis de la historia de la metafísica, desde la óptica nietzscheana, en el que se trata de describir de manera alegórica la forma como el platonismo convalida la metafísica de occidente a través de todo su discurrir. Asimismo, revela el desafío que le plantea el filósofo alemán a Platón en toda su obra, a partir del cual imprime su impronta en la historia de la filosofía que Nietzsche hace.

El texto habla por sí solo; sin embargo, Cruz Vélez se da a la tarea de explicarlo y ubica seis momentos importantes en la historia de la filosofía.

El primero es el de la génesis de la metafísica. En la frase de Nietzsche "yo, Platón, soy la verdad"está concentrada la semilla de la metafísica; en esta se expresa no solo que Platón es su fundador, sino que, a través del juego literario,enmarcado en frases como "el mundo verdadero, accesible al sabio, al piadoso, al virtuoso...", se está criticando de manera irónica las características fundamentales de esa disciplina. Dentro de estas se encuentran la escisión de la realidad, que da lugar a un dualismo cosmológico, epistemológico y ético. Este tiene implícito una caracterización casi 
peyorativa del mundo sensible, del devenir, de lo fáctico y de lo material, que se entiende en contraste del mundode las ideas.Este último se concibe como el mundo verdadero, asequible solo al hombre sabio y virtuoso, quien hace uso de su razón y desdeña los sentidos.

El segundo momento corresponde a la temprana Edad Media. El platonismo se fusiona con el cristianismo.Si en el primer momento la razón fue presentada como el camino para acceder al mundo verdadero, ahora es la fe quien cumple esta misión. Por esto, el mundo verdadero o eidos de Platón es equiparado con el cielo de los cristianos; la verdad se aleja aún más del reino de la physis, que ahora se ve como un "valle de lágrimas", en el que se llega a purgar nuestra enfermedad mortal, producto del pecado original, que,según la antropología agustiniana, es explicada como propia del hombre de alma enferma.

Ya no es el filósofo, ni siquiera el místico, quien puede llegar a la verdado cielo: este lugar está reservado para el santo, quien con una fe ciega en lo que no ve, tiene la capacidad de negar el mundo que ve y en el que está.

Los varones de Dios cumplen dicha misión, cual nobles caballeros que en su heroica tarea por cotejar la reina se ven obligados anegarse a sí mismos, superando miedos, temores y las propias comodidades, placeres y lujos que les brinda su posición. Asimismo, el santo es quien logra superar las concupiscencias y placeres bajos del cuerpo, que aún es visto como cárcel del alma.Esto se logrará por medio del ayuno, la abstinencia, la penitencia y las demás prácticas recomendadas por la fe y la tradición cristiana.

El tercer momento de la metafísica, que logra establecer Cruz Vélez, a partir de la cita de Nietzsche, corresponde al siglo XVIII europeo. La crítica escéptica de la ilustración logra hacer grandes fisuras a los fundamentos del mundo sobrenatural del cristianismo. El hombre de este tiempo invalida el cielo para instalarse como amo y señor del mundo natural: de ahí la frase hominus deus in terris. Kant presenta una de las premisas más importantes de esta época, que va a servircomo supuesto que no se tematiza y que, por el contrario, convalida no solo las instituciones del momento, sino la ciencia misma, que es presentada como el nuevo "mesías" de la humanidad. Este supuesto es "loúnico cognoscible es el mundo sensible, al que solo se puede llegar por medio de la experiencia. El mundusintelligibilises incognoscible". 
No obstante lo anterior, el mundusintelligibilis sigue vigente. El hombre, asegura Kant, no se puede reducir a un mero fenómeno natural; de hecho, este, en esencia, es libertad, de ahí que este sea un habitante de los dos mundos.

El mundusintelligibilis, a pesar de estar fuera de la posibilidad de conocerse, se convierte en un imperativo de la razón práctica. No se puede conocer y mucho menos demostrar,pero es una necesidad que está dentro del ámbito del deber ser, y, por eso, se convierte en una sutil vanidad que nos recuerda que somos el centro de la creación, en cuanto que el mundusintelligibilis nos pone a la altura del reino de los fines, por encima de nuestra condición natural. Este mundo inteligible, asegura Cruz Vélez, es el mismo viejo sol de Platón al que se refiere Nietzsche, haciendo alusión a la metáfora del mito de la caverna. Eneste, la idea del bien está representada por el sol, un sol anémico sin el mismo brillo, después de haber pasado por la mirada inquisidora de la ilustración o como dice el mismo filósofo colombiano: "El viejo sol aparece descolorido después de haber pasado a través de la crítica de la ilustración y del gélido paisaje de Königsberg, donde la fría cabeza de Kant hacía los últimos esfuerzos por no dejarla ocultar" (Cruz Vélez, 1997, p. 30).

El cuarto momento de la metafísica, que se aprecia en la cita de Nietzsche, corresponde al positivismo del siglo XIX. Una vez superado el mundusintelligibilisde Kant y tomada en serio su premisa de que lo único cognoscible es el mundo sensible, se logra despertar a la razón de su sueño dogmático. Comienza a aparecer un nuevo sol que ilumina a la humanidad con una luz de rebeldía, puesto queadvierteque no está bien obedecer a algo que por esencia no se puede conocer.

En los dos últimos momentos, Nietzsche entra en escena con un nuevo "libreto", por medio del cual logra redefinir todo el orden establecido. Danilo Cruz Vélez admite la innovación, preponderancia y alcance de la filosofía nietzscheana, al punto de afirmar que la metafísica vigente sobre la cual está sostenida toda la época de la técnica en que vivimos es la del filósofo alemán. A pesar de lo anterior, disiente de la pretensión del filósofo vitalista de considerar que su propuesta filosófica se da dentro de un horizonte y unos presupuestos que se sustraen de la metafísica. Una de las pruebas contundentes de que Nietzsche tiene una metafísica las encuentra en la cita que se acaba de introducir; en esta, se ve claramente que,sin importar que el pensamiento de Nietzsche se mueva en una dirección contraria de la metafísica tradicional platónica, se apoya sobre el mismo suelo de la metafísica. De hecho es esta perspectivala que posibilita y motiva su obra y su pensamiento. Por esto, en la cita 
del Crepúsculo de los ídolos, se evidencian unas líneas de continuidad que permiten observar el pensamiento y la obra del filósofo alemán; estas están circunscritas en la historia de la metafísica, como consecuencia de una interpretación antagónica del platonismo, que es el suelo de toda la metafísica de occidente. Para corroborar lo anterior, se seguirá rastreando las dos últimas interpretaciones que hace Cruz Vélez de la cita del Crepúsculo de los ídolos.

En la explicación de la quinta parte, en un pequeño párrafo, Cruz Vélez da muestra de su erudición y rigurosidad (de no ser porque este estudio, como se demostrará a continuación es el mismo de Heidegger). El pensador colombiano señala de manera cronológica los diferentestextos de Nietzsche en los que afirma y demuestra que la historia dela idea del mundo verdadero no es más que la historia de un error:la idea del mundo verdadero no es más que una fábula. El sol de Platón, al igual que el eidos, resultaron ser una quimera, producto de las elucubraciones del filósofo ático. Ahora, la tarea es deshacernos de estas concepciones, para que comience un nuevo día con luz propia que nos permita superar las sombras de Platón.

La sexta y última parte corresponde al epílogo del pensamiento de Nietzsche. Este está representado porla figura de Zaratustra, que viene a ser un mesías que anuncia la nueva filosofía que tiene como soporte el mundo físico y que,por otro lado, denuncia al gran impostor de la historia. El texto Así habló Zaratustra, cuya primera parte es de 1883, coloca a Nietzsche en el pleno mediodía de la historia o, como lo expusiera el mismo autor de manera poética, “[...] mediodía: momento de la sombra más corta; fin del más antiguo error; cumbre de la humanidad [...]” (1998, p. 25).

Zaratustra provocó el diluvio con el que se borró la historia de un error porel cual se había persuadido en la existenciade un mundo verdadero sobre la base de una idea que resultó ser una quimera. Ahora nos invita a vivir en este mundo físico, que ya no es reflejo ni apariencia de otro mundo más perfecto, sino una única realidad.

De lo anterior se vale Cruz Vélez para probar que la filosofía de Nietzsche se mueve en el piso de la metafísica. La razón de esto es que el objeto de estudio de esta rama de la filosofía es el ser en cuanto ser, que corresponde a la respuesta a la pregunta “¿qué es lo ente, lo que es, en cuanto tal?”. Esta pregunta, de manera subrepticia, motiva todo el pensamiento de Nietzsche y encuentra en su filosofía una respuesta; esta respuesta se presentó, de manera general, en la quinta y sexta parte de la explicación 
de la cita El Crepúsculo de los ídolos, es decir, en el que se explicó el platonismo al revés en el que cae Nietzsche.

Si la metafísica se redujera a su mera definición etimológica quedaría claro que Nietzsche no es un filósofo que se pueda clasificar bajo esta disciplina, dado que el esfuerzo de su trabajo intelectual está dirigido justamente a negar ese más allá de la physis creado por Platón y que tuvo anquilosado al mundo hasta la aparición de Zaratustra.

Al quedar negado el "mundo verdadero", automáticamente surge una pregunta sobre qué es lo que queda, es decir, la pregunta por el ser de las cosas. Esta es justamente la región en la que se mueve la metafísica y toda la obra de Nietzsche.

\section{Parámetros de comparación entre Danilo Cruz Vélez y Heidegger en torno a la metafísica nietzscheana}

Antes de exponer cuál es la región metafísica en la que a juicio de Danilo Cruz Vélez opera Nietzsche, es conveniente seguir confrontando las tesis del profesor colombiano con las de Heidegger en torno al estudio realizado hasta ahora, puesto que al confrontarlos nos daremos cuenta que Danilo Cruz Vélez retoma los estudios del filósofo alemán, incluyendo la citas y el marco de interpretación. La única diferencia que se puede resaltar es que Martin Heidegger hace la claridad de que la cita, si bien está en la obra El Crepúsculo de los ídolos, hace parte de La voluntad de poder (1975, pp. 567, 568), que fue publicada en 1888, mientras que Cruz Vélez solo trae a colación El crepúsculo. Se puede citar directamente la obra de Nietzsche, puesto que los dos pensadores que se están trabajando hablan de esta. No obstante, el propósito es señalar y confrontar los estudios de Heidegger con los de Cruz Vélez. Por esto, en este caso nos vemos obligados a referenciar la cita de Nietzsche. Este trabajo se encuentra publicado en dos textos diferentes:por un lado, en el primer tomo del Heidegger sobre Nietzsche, y, por el otro, en Nietzsche 125 años. En este caso tendremos en cuenta el último texto. Comencemos con el preámbulo de Heidegger:

En la obra "El Ocaso de los Ídolos" redactada en pocos días, en el último año de creación (septiembre de 1888) y publicada solamente en el año de 1899, hubiera debido llamar la atención una sección cuya posición fundamental la diferencia de todas las otras conocidas. La sección lleva por título: “De cómo 
el 'mundo verdadero' terminó por devenir una fábula. Historia de un error" [VIII, 82/83; correspondiente a Nietzsche] (1975, pp. 567-568).

La sección abarca algo más de una página (se conserva el manuscrito autógrafo de Nietzsche).

El título "De cómo el 'mundo verdadero' terminó por devenir una fábula" quiere decir que ahí en ese fragmento va a ser expuesta la historia del desarrollo por el cual no solo lo suprasensible, colocado por Platón como lo realmente verdadero, va a descender del rango supremo que ocupaba, al rango inferior, sino que va a hundirse en lo irreal, volviéndose nulo. Nietzsche articula esa historia en seis etapas en las que es fácil reconocer las épocas más importantes del pensamiento occidental, y que desembocan inmediatamente en el umbral de su propia filosofía. (Heidegger, 1977, pp. 120-130)

Una pequeña diferencia que se aprecia en todo el texto es el hecho de que el profesor Cruz Vélez insiste en llamar escenas a cada una de las seis partes con las que Nietzsche, de manera alegórica, hace referencia a la historia de la metafísica en occidente, en razón a que considera que la cita del Crepúsculo de los ídolos tiene la estructura de un plan de trabajo de un dramaturgo, mientras que Heidegger simplemente se limita a enumerar cada parte y, además, va introduciendo, con el propósito de realizar una exégesis, cada una de las frases que analiza y explica. En este sentido, Cruz Vélez, en cambio, introduce toda la cita para luego explicarla. Sin embargo, esta diferencia es algo accesorio, puesto que, al entrar a analizar el texto de manera rigurosa, se evidencia que las ideas centrales y las argumentaciones son las mismas.

1. 'El mundo verdadero accesible al sabio, al piadoso, al virtuoso, este vive en él, es él'. Aquí la fundamentación de la doctrina se establece a través de Platón. Aparentemente no se trata del verdadero mundo, sino de la manera como el hombre se relaciona con él, y de saber hasta qué punto es alcanzable. Y la determinación esencial del mundo verdadero reside en el hecho de ser accesible aquí y ahora al hombre, si bien no para cualquiera y sin más. Él es accesible al virtuoso, es lo suprasensible. Lo que implica que la virtud consiste en la renuncia a lo sensible, en cuanto al ser del ente pertenece la negación del mundo sensible inmediato. Aquí el 'mundo verdadero no es todavía platónico, es decir, no es 
todavía inalcanzable, y solamente deseable, puro 'ideal'. PLATÓN es el que es, en cuanto trata en forma escueta y terminante de ese mundo de las ideas como esencia del ser. Lo suprasensible es idea; este objeto de la visión es visto realmente con los ojos del pensamiento y de la existencia griegos, y experimentado en ese sencillo acto de ver como lo que posibilita a todo ente, en cuanto ser-presente, a ser él mismo. (Véase De la esencia del fundamento, 1929. Sección II). De ahí que Nietzsche agregue entre paréntesis a título de aclaración: “(la más antigua forma de la idea, relativamente sabia, simple, convincente. Es una paráfrasis de "yo, Platón, soy la verdad”)". El pensar de las ideas y la correspondiente interpretación del ser son en sí y por sí mismos creadores. La obra de Platón no es todavía platonismo. El 'mundo verdadero' no es objeto de una doctrina sino que es el poder de la existencia, lo que brilla al ser presente, el puro aparecer sin encubrimiento. (Heidegger, citado en Pérez Mantilla, 1977, p. 23)

En la primera sección, la idea preponderante fue la de que Nietzsche le atribuye a Platón la creación de la metafísica de Occidente a partir de la teoría de los dos mundos. Veamos la manera como los dos investigadores lo expresan y explican:

Cruz Vélez lo dice de este modo: "[comienzos del siglo IV a. C., en Atenas. Platón funda la metafísica. La fundación se efectúa en un movimiento de la razón hacia otro mundo, que se considera como el verdadero [...]”. Martin Heidegger lo expresa así: “[a]quí la fundamentación de la doctrina se establece a través de Platón [...] Platón es el que es, en cuanto trata en forma escueta y terminante de ese mundo de las ideas como esencia del ser".

2. El mundo verdadero, inaccesible ahora, pero permitido al sabio, al piadoso, al virtuoso ('al pecador que hace penitencia'). Ahora, junto con la posición de lo suprasensible como el verdadero ser, es expresamente establecida la ruptura con lo sensible, pero nuevamente no del todo: el mundo verdadero es inaccesible solo en esta vida, época de la existencia terrestre. Esta misma, si bien obtiene debido a ello una desvalorización, obtiene también su tensión propia, pues lo suprasensible es prometido como más allá. La tierra se convierte en lo 'terrenal'. En la esencia y en la existencia del hombre se produce una fisura que permite al mismo tiempo una ambigüedad. Comienza la posibilidad del sí y del no, del tanto lo uno como lo otro; el aparente decir sí a lo de acá [Diesseits], pero con una reserva: el poder participar en lo de acá pero siempre dejando abierta la más lejana y extrema de las puertas traseras. En vez del modo de ser, compacto y no 
por ello anodino, sino apasionado de los griegos, fundado en lo accesible y que se traza aquí su límite; que no solo soporta las decisiones del destino sino que afirmándose conquista la victoria, se instaura lo insidiosamente ilusorio. En lugar de Platón domina ahora el platonismo. En consecuencia: "Progreso de la idea, se hace más sutil, insidiosa, inaprensible: se vuelve mujer, se vuelve cristiana [...]”. Lo suprasensible no se halla más en el ámbito de la existencia humana, presente en ella y sus cosas sensibles, sino que la totalidad de la existencia humana se convierte en lo de acá, en cuanto lo suprasensible es interpretado como el más allá. El mundo verdadero se hace ahora todavía más verdadero, en cuanto cada vez se separa más de lo de acá; adquiere cada vez más ser, mientras se vuelve algo prometido, mientras más solícitamente se persevera y se cree en él como algo prometido. Si comparamos esta segunda etapa de la historia con la primera, entonces vemos cómo Nietzsche en la exposición de la primera etapa separa a Platón y lo defiende de todo platonismo. (pp. 124-125)

El propósito de la segunda parte de este texto fue señalar la forma como el platonismo se filtra en la Edad Media y se sincretiza con el cristianismo. Se resaltó el hecho de que la razón pierde fuerza como medio para acceder al otro mundo y es remplazada por la fe. De esta manera, el mundo de las idea se hace "mujer", en la medida en que su acceso ya no es a través de la razón calculadora, sino por medio de la penitencia y de los cortejos de la fe y la religión. Por esta razón,el mundo de las ideas se hace “cristiano". Cruz Vélez lo expresa así: "[t]emprana Edad Media. El platonismo se funde con el cristianismo [...] la relación entre el hombre y el otro mundo mediante la razón se debilita poco a poco, hasta llegar a ser sustentada solo por la fe [...] el trato con ella exige rodeos y esguinces como si fuera una mujer" (Cruz Vélez, D. 1997). Heidegger lo expresa de esta manera: “en lugar de Platón predomina ahora el platonismo. En consecuencia: 'progreso de la idea, se hace más sutil, insidiosa, inaprensible: se vuelve mujer, se vuelve cristiana' [...]”. Llama la atención el hecho de que no solo la interpretación es la misma, al igual que en la primera sección, los ejemplos o comparaciones son las mismas.

3. El Mundoverdadero inaccesible, indemostrable, no prometible pero ya, en cuanto pensado, un consuelo, una obligación, un imperativo'. Esta etapa designa aquella forma del platonismo alcanzada mediante la filosofía de Kant. Lo suprasensible es ahora un postulado de la razón práctica; aun fuera de toda posibilidad de experimentarlo y de probarlo, viene exigido como necesariamente existente, con el objeto 
de salvar un fundamento suficiente para la legalidad de la razón. Es verdad que se duda críticamentede que por el camino del conocimiento se pueda tener acceso a lo suprasensible, pero solo con el objeto de dejarle espacio a la fe en las exigencias de la razón. En la existencia y estructura de la imagen cristiana del mundo, Kant no introduce ningún cambio, como no sea el que la luz del conocimiento cae ahora sobre la experiencia, es decir, sobre la interpretación físico-matemática del 'mundo'. Lo que queda fuera del conocimiento de las ciencias físicas y naturales, no es negado en su existencia, pero sí desplazado al lugar indeterminado de lo incognoscible. De ahí que Nietzsche pueda decir: 'el viejo sol a fin y al cabo, solo que a través de la neblina y del escepticismo; la idea se ha hecho sublime, pálida nórdica, koenigsberguiana'. Un mundo transformado frente a la sencilla claridad de la relación inmediata que Platón mantuvo con lo suprasensible, en cuanto ser vislumbrable Nietzsche ve, en cuanto adivina el platonismo innegable de Kant, también la distancia esencial de ambos diferenciándose así fundamentalmente de sus contemporáneos, que, no por casualidad, identificaron a Kant con Platón, si es que no interpretaron a Platón como un kantiano malogrado. (Heidegger, citado en Pérez Mantilla,1977, pp. 125-126)

La tercera etapa hace referencia a la crítica restrictiva de la ilustración moderna a la idea platónica. "Curiosamente”los dos pensadores no solo hacen la misma interpretación, sino que matizan la misma idea apelando a Kant, en cuanto este es el primero en afirmar la imposibilidad de conocer el mundo inteligible. De manera especial, llama la atención el hecho de que las metáforas y analogíasutilizadas por Heidegger a la hora de referirse a Kant son las mismas utilizadas por Danilo Cruz Vélez. Quizá lo único en lo que difieren es la traducción. El pensador colombiano se refiere en los siguientes términos: “[e]l viejo sol aparece descolorido después de haber pasado a través de la crítica de la ilustración y del gélido paisaje nórdico de Königsberg, donde la fría cabeza de Kant hacía los últimos esfuerzos por no dejarla ocultar". Heidegger por su parte lo expresa de la siguiente forma: “[d]e ahí que Nietzsche pueda decir: 'El viejo sol al fin y al cabo, solo que a través de la neblina y del escepticismo; la idea se ha hecho sublime, pálida nórdica, Koenigsberguiana'.

Otro aspecto que se puede advertir es que Heidegger le da el crédito a Nietzsche respecto de la metáfora poética con la que se refiere este a Kant, mientras que Cruz Vélez la asume como suya, no coloca cita pie de página, ni comillas, ni un párrafo 
o frase introductoria que permita aclarar que la idea y la redacción de la misma correspondea Nietzsche.

4. El mundo verdadero, ¿inaccesible? En todo caso, inalcanzado. Y en cuanto inalcanzado también desconocido. En consecuencia tampoco puede servir de consuelo, no puede ser liberador, no puede obligar: ¿a qué podría obligarnos algo desconocido? [...]". En esta cuarta etapa se fija históricamente aquella forma del platonismo que se suprime a sí misma con base en la filosofía kantiana que la precede, pero sin que se produzca una superación originalmente creadora. Es la época posterior al dominio del idealismo alemán, hacia la mitad del siglo pasado. El sistema kantiano es desenmascarado y hecho saltar con ayuda de su principio fundamental de la incognoscibilidad teórica de lo suprasensible. Si el mundo suprasensible. Si el mundo suprasensible es inaccesible al conocimiento,entonces no podemossaber nada de él y en consecuencia no podemos decirnos ni por él y en contra de él. Se hace visible que lo suprasensible no llega a la filosofía kantiana debido a susprincipios fundamentales de orden gnoseológico, sino a causa de presupuestos teológico-cristianos no destruidos. En relación con esto Nietzsche observa alguna vez refiriéndose a Leibniz, Kant, Fichte, Schelling, Hegel, Schopenhauer: 'Todos son solamente tejedores de velos' (XV, 112); la frase es equívoca; ella significa no solamente que son en el fondo teólogos encubiertos, sino que como la palabra lo dice (Scheleier-Macher), son hacedores de velos, velan las cosas, frente a eso, el rechazo, aunque burdo, de lo suprasensible como algo desconocido, al que según Kant no puede llegar fundamentalmente ningún conocimiento, es, dentro de la insidia y la 'falsificación' imperantes con la llegada del, platonismo, la alborada de una meditación honrada. De ahí: 'Mañana gris. Primer bostezo de la razón. Canto del gallo de positivismo’. Nietzsche ve el surgir de un nuevo día. La razón, o sea, el saber y el preguntar del hombre, se despierta. ((Heidegger, citado en Pérez Mantilla,1977, p. 127)

En la siguiente sección, se muestra el radicalismo del positivismo, al llevar a sus últimas consecuencias la tesis de Kant sobre los límites del conocimiento. Si no hay acceso al conocimiento del mundo inteligible, es inoficioso hacer cábalas sobre este, de ahí que no exista más conocimiento que el conocimiento de lo sensible. Al igual que en las secciones anteriores, las metáforas, las citas y los argumentos son los mismos. El pensador colombiano dice, refiriéndose al tema en cuestión: “[c]omienza, a salir de nuevo la luz, comienza a despejarse la oscuridad creada por Platón, y la razón 
despierta del sueño dogmático”. Heidegger lo expresa de la siguiente manera: “[...] la alborada de una meditación honrada. De ahí: 'Mañana gris. Primer bostezo de la razón. Canto del gallo del positivismo'. Nietzsche ve el surgimiento de un nuevo día”.

La razón, osea, el saber y el preguntar del hombre, se despierta. Por otro lado, Heidegger, en el momento de explicar el hecho de que Nietzsche criticara a todos los filósofosmodernos predecesores de él, que hicieron una apología del mundo inteligible, los enumera a todos, mientras que Cruz Vélez hace una generalización, en donde afirma que el intento de salvar el mundo inteligible kantiano, Nietzsche lo tipifica como prejuicios de orden teológico, de cualquier manera la idea y argumentación es explícitamente la misma, solo es cuestión de estilo.

5. 'El 'mundo verdadero': una idea que ya no sirve para nada, ni siquiera obliga ya, una idea que se ha vuelto inútil y superflua, en consecuencia una idea contradicha: ¡eliminémosla!'. Mediante esta etapa Nietzsche designa ya el primer paso en el camino de su filosofía propia. Al ¿mundo verdadero' lo escribe ahora ente comillas. Esa no es ya más una frase suya, cuyo contenido podría afirmar. El 'mundo verdadero' es suprimido; pero démonos cuenta del motivo: porque se ha vuelto inútil y superfluo. Con la luz del alba surge una nueva medida: lo que no concierne a la existencia humana no tieneningún derecho a ser afirmado. En consecuencia: 'día claro; desayuno; retorno del buen sentido y de la serenidad; rubor de Platón; estruendo infernal de los espíritus libres'. Nietzsche piensa aquí en los a los de su propia transformación a la que alude claramente el título de las obras aparecidas por esa época: Humano, demasiado humano (1878), El viajero y su sombra (1880), Aurora (1881) y La gaya ciencia (1882). El platonismo es superado, en tanto que [sic] el mundo verdadero en cuantomundo suprasensible es superado, pero queda el mundo sensible del que se adueña el positivismo. La discusión es ahora con él. Porque Nietzsche no quiere permanecer en un amanecer, ni reposarse en una mañana. A pesar de la supresión del mundo suprasensible como mundo verdadero, queda todavía el espacio vacío de esa dimensión superior y el plano de un arriba y un abajo: el platonismo. Aquí todavía es necesario hacer preguntas. (p. 127)

La explicación de los dos pensadores que se confrontan a la hora de explicar la quinta parte es exactamente la misma. Adicional a esto, es de llamar la atenciónque Danilo Cruz Vélez cita las mismas obras de Nietzsche que menciona Heidegger a la hora de explicar cómo Nietzsche entra en escena, haciendo ver cómo la historia de la metafísica de occidente es la historia de un error. 
6. Hemos suprimido el mundo verdadero, ¿qué mundo ha quedado? ¿Acaso el aparente? [...] ¡De ningún modo! Al suprimir el mundo verdadero hemos suprimido también el aparente. El que Nietzsche haya agregado una sexta etapa, muestra que él quiere ir más allá de sí mismo y de la simple superación de lo suprasensible. En la movilidad del estilo y de la grafía puede uno advertir cómo es la claridad de este paso, la que lo lleva a la total transparencia en que lo vago desaparece. De ahí: 'Mediodía, instante de la más corta sombra; fin del más largo error; O sea, el comienzo de la última etapa de su propia filosofía'. (pp. 128-131)

En la última parte, los dos escritores coinciden en señalar que el texto muestra la entrada en escena de Nietzsche, a través de su personaje Zaratustra. Danilo Cruz lo expresa de la siguiente manera: “[...] aquí entra en escena Zaratustra, que anuncia el comienzo de la filosofía positiva de Nietzsche, de la filosofía que viene después de la filosofía negativa". Heidegger, por su parte, lo dice en los siguientes términos: "[d]e ahí: Medio día, instante de la más corta sombra; fin del más largo error; punto supremo de la humanidad; incipitZaratustra'. O sea, el comienzo de la última etapa de su propia filosofía”. Se observa nuevamente el cuidado por parte de Heidegger a la hora de citar. En esta última parte, a diferencia de las anteriores, Danilo Cruz Vélez introduce dos tipos de ideas para matizar y explicar el texto que no fueron tenidas en cuenta por Heidegger. Laprimera idea que usa el profesor colombiano se ve en el momento en que explica la alegoría de Nietzsche sobre el mediodía. Para explicar esta metáfora, Cruz Vélez trae a colación una de las cartas que el filósofo alemán enviara a su amigo Paul Deusen, en la que, de manera expresa, le dice que la tarea que va adelantar divide la humanidad en dos. Por otro lado, el escritor colombiano ilustra esta última parte del texto de Nietzsche con los animales de Zaratustra. Curiosamente, Heidegger en su texto El eterno retorno de lo mismo, publicado en el primer tomo de Heidegger sobre Nietzsche, hace todo un estudio hermenéutico sobre los animales de Zaratustra. En este se evidencia la misma interpretación y sentido que expresaría Danilo Cruz Vélez en su estudio.

Con lo anterior queda claro cómo todo el estudio realizado por Danilo Cruz Vélez en torno a la filosofía de Nietzsche como un platonismo invertido así como la exégesis que demuestra que la metafísica de Occidente ha sido permeada en su totalidad por Platón no es más que una buena traducción de los apuntes tomados por el profesor colombiano cuando asistió a los seminarios de Heidegger. 
Aparte de lo mencionado anteriormente, hay todo un subcapítulo del tomo uno Páginas 189 a la 198, en donde Heidegger aborda, de manera rigurosa, el intento de Nietzsche de hacer una inversión del platonismo a partir de la experiencia fundamental del nihilismo. Son 10 páginas que permiten corroborar que las tesis de Danilo Cruz Vélez respecto a la metafísica de Occidente como un platonismo derivado de la teoría de los dos mundos son un calco de Heidegger. De igual forma, en "La verdad en el platonismo y en el positivismo”, Heidegger hace una exégesis sobre la inversión del platonismo que realiza Nietzsche.

La primera tesis de Cruz Vélez, según la cual a Nietzsche hay que ubicarlo dentro del horizonte de la metafísica, corresponde justamente al título del primer subcapítulo de la parte primera del tomo uno de Heidegger sobre Nietzsche. En este este, Heideggerexpone que el pensamiento de Nietzsche en su totalidad reposa sobre la base de la pregunta por el ser del ente, y que, de manera contundente, Nietzsche más allá de ser un filósofo de la vida, es un filósofo metafísico o teórico.

Quizá sean los subcapítulos 20 y 24 de la primera parte del primer tomo de Heidegger sobre Nietzsche en los quese hace más notoriala manera como el profesor colombiano se apropia del trabajo del filósofo de la selva negra. En"La verdad en el platonismo y el positivismo", Heidegger defiende nuevamente la idea de que Nietzsche es un filósofo metafísico, pues emprende una crítica contra la metafísica de occidente que se funda sobre la base de la teoría de los dos mundos de Platón. En esas circunstancias, el trabajo de Nietzsche es un esfuerzo por hacer una inversión del platonismo.

\section{Nihilismo como el final de la metafísica}

Al negar el mundo verdadero, no solo se afirma el mundo aparente como única realidad, dado que este mundo aparente existe en relación con el supuesto mundo verdadero, sino que, aparte de esto, como consecuencia de lo anterior, se dan dos hechos preponderantes en la metafísica de Nietzsche: el primero es la muerte de Dios, y el segundo, el más importante para nosotros, es el del nihilismo.

La muerte de Dios, como lo asegura el mismo Danilo Cruz Vélez, no se puede entender como un problema personal de Nietzsche, sino como una consecuencia inherente de la volatilización del mundo verdadero. Dios es un concepto abstracto, con el que se trata de dar explicación y fundamento al "mundo verdadero". Con la desaparición 
de este último, al mismo tiempo tendrá que morir la idea de Dios. Por esta razón, la muerte de Dios en la filosofíade Nietzsche se expresa como una situación histórica del hombre y de la cultura de occidente y no una experiencia personal del filósofo.

Por otro lado, la expresión Gottitisttot [Dios ha muerto] no hace referencia expresa al dios del cristianismo, sino a toda deidad y divinidad generada como consecuencia del mundo suprasensible, como la idea de bien supremo de Platón, el motor inmóvil de Aristóteles, la idea de eternidad de Descartes, el panteísmo de Spinoza, el panlogismo de Hegel y a cualquier otra modificación de ese mundo verdadero, como ideales, imperativos, principios y demás instancias trascendentales. Estas concepciones, de hecho, tienen que desaparecer con el fenómeno nihilista, que es justamente la ausencia de ideas rectoras o, dicho en otras palabras, la caducidad del mundo suprasensible.

Estas tesis están explícitas en la obra de Heidegger. Veamos:

\begin{abstract}
Nietzsche utiliza el término 'nihilismo' para designar el movimiento histórico que él reconoció por vez primera, ese movimiento ya dominante en los siglos precedentes y que determinará el siglo próximo, cuya interpretación más esencial resume en la breve frase: 'Dios ha muerto'. Esto quiere decir: el 'Dios cristiano' ha perdido su poder sobre el ente y sobre el destino del hombre. El 'Dios cristiano' es al mismo tiempo la representación principal para referirse a lo 'suprasensible' en general y a sus diferentes interpretaciones, a los 'ideales' y 'normas', a los 'principios' y 'reglas' a los 'fines' y 'valores' que han sido erigidos 'sobre' el ente para darle al ente en su totalidad una finalidad, un orden $\mathrm{y}$ - tal como se dice resumido- 'un sentido'. El nihilismo es ese proceso histórico por el que el dominio de lo 'suprasensible' caduca y se vuelve nulo, con lo que el ente mismo pierde su valor y su sentido. (Heidegger, 2000b, p. 34)
\end{abstract}

Aparte de la cita que se acaba de introducir, la cual resulta explícita, de modo que serviría como referencia a lo expresado por el profesor colombiano, se sugiere leer el capítulo sobre el nihilismo como "desvalorización de los valores supremos" Tomo II Páginas 43 y siguientes; así como el capítulo “Nihilismo, nihil y nada”.

El propósito de Heidegger, en la parte uno del primer tomo, es hacer una reconstrucción fenomenológica que permita presentar la voluntad de poder como arte. Para este 
fin, hace un estudio riguroso, el cual queda consignado en un escrito de alrededor de 200 páginas, organizadas, a la vez, en 25 subcapítulos.

Por otro lado, es aquí donde Heidegger esgrime una de las formulas para caracterizar el nihilismo en relación con la muerte de Dios y la culminación de la metafísica de Occidente. Tambiénofrece allíuna explicación acercade la necesidad de ver la muerte de Dios no como la expresión de un posición atea y personal de Nietzsche, sino como una experiencia histórica de occidente. Estas ideas son expuestas por el investigador colombiano de manera explícita, como se puede corroborar en los parámetros de comparación expuestos en los anexos y en el resumen del trabajo del pensador colombiano que se presentó en la sección "Análisis general del texto de Danilo Cruz Vélez sobre nihilismo y metafísica".

Según Cruz Vélez, las ideasdel fin de la metafísica, de la volatilización del "mundo verdadero"y de la muerte de Dios designanun mismo fenómeno visto desde distintas perspectivas. Es por esto que ha de entenderse el fin de la metafísica como la superación de la teoría de los dos mundos. Este hecho da lugar a la volatilización del mundo verdadero y, por ende, la muerte de Dios, que es su fundamento al igual que la superación de todo ideal, imperativo y principio que se desprendan de dicha metafísica.

Como consecuencia de lo anterior, se supera toda visión teleológica de la historia y de la humanidad, puesto que, al no existir ningún imperativo verdadero o supremo, queda imposible postular o declarar algún sentido o finalidad a la existencia. Por esta razón, se cae en un vacío, en un nihil, en una cultura sin ideas rectoras, y esto es justamente el nihilismo, según Nietzsche, es decir, el proceso mediante el cual los valores supremos pierden su valor.

De esta manera, se ha logrado acumular el material necesario para a afirmar que el nihilismo nietzscheano ha de entenderse desde la óptica de Danilo Cruz Vélez como el punto en donde convergen los principales temas metafísicos del filósofo alemán, tales como el fin de la metafísica, la volatilización del mundo verdadero y la muerte de Dios. Es por esto que el nihilismodebe interpretarse como uno de los temas preponderantes de la metafísica. Debido a esto, Cruz Vélez asegura “[...] el nihilismo, en efecto, es lo que tiene que ver con la nada (nihil) que es un tema central de la metafísica” (Cruz Vélez, 1972) 
Demostrar que el nihilismo hace parte de los temas centrales de la metafísica y que dicho término es introducido de manera estricta por primera vez en el ámbito de la filosofía por Nietzsche, se convierte en otra prueba contundente para Cruz Vélez de que la crítica a la metafísica de Occidente de la obra de Nietzsche se realiza desde el mismo seno de la metafísica.

De hecho el nihilismo tiene que ver con la nada, y si bien es cierto que el tema central de la metafísica es el ser y no la nada, también hay que reconocer, asegura Cruz Vélez, que el tema del ser, siempre ha estado asociado desde sus orígenes con la nada. Con el fin de la metafísica, que había alcanzado su máxima expresión con Hegel, los modelos y esquemas con los que se venía interpretando el ser de las cosas entran también en desuso, y el concepto de nada entra a reemplazar al de ser y se sitúa, de esta manera, dentro de los horizontes de la metafísica.

Quizá esta última idea, a diferencia de las anteriores, es la más original del pensador colombiano, pues no se encontró explícitamente en los trabajos de Heidegger. Sin embargo, hay que hacer claridad en que esta idea, si prestamos atención a la referencia, fue extraída de otro texto diferente al que se está trabajando en este capítulo. Si nos atenemos al texto analizado en esta sección, nos daremos cuenta que los argumentos y tesis presentados por Cruz Vélez, según el cual Nietzsche defiende una metafísica de la subjetividad, están explícitos en los trabajos de Heidegger.

Ese trabajo amerita una sesión aparte, que se trabajará a continuación.

\section{Nietzsche y la metafísica de la subjetividad}

Aún queda por resolver parte del problema que se planteó al comienzo de este capítulo:el de que Nietzsche, a pesar de criticar a la metafísica de Occidente, está comprometido con afirmaciones metafísicas. De este modo solo criticaría un tramo de la metafísica desde el seno de esta. A este respecto el profesor colombiano pregunta:

¿Supera Nietzsche la metafísica y llega esta con él, en verdad, a su fin? Nietzsche se plantea de nuevo la pregunta inicial de la filosofía: ¿Qué es lo ente en cuanto tal? Todo lo que hay, es decir, lo ente en total, es para él el mundo. Por ello, su pregunta es propiamente ¿Qué es el mundo en cuanto tal? (Cruz Vélez, 1997, p. 47) 
La pregunta fundamental de la filosofía, a la cual se refiere Cruz Vélez en la cita, es también la de la metafísica y espor el ser del ente. El autor, de manera explícita, manifiesta que Nietzsche no logra estar al margen de la metafísica. Por otro lado, hace claridad sobre la pregunta y la respuesta a la cuestión por la naturaleza del ente en cuanto tal. Nietzsche atribuye al mundo los atributos propios del ser del ente. A partir de ahíse formula una nueva pregunta: ¿qué es el mundo en cuanto tal? Al ubicar la cita en el contexto general de la cual fue extraída, Danilo Cruz Vélez hace una exégesis rigurosa, que permite resolverla. La superación de la situación histórica que se derivó del platonismo, que concedió un mayor orden o rango ontológico al mundo suprasensible, debida a Nietzsche, da lugar a nuevas tesis metafísicas, como la volatilización del mundo de la razón, la muerte de Dios y el nihilismo. En este sentido solo queda el mundo sensible del devenir, es decir, el mundo de Heráclito.

En este mismo contexto, Cruz Vélez muestra la relación estrecha entre Heráclito y Nietzsche, pero deja ver también la forma como Nietzsche logra tomar distancia de los presocráticos, al introducir conceptos metafísicos a la hora de referirse al mundo de la physis. Por esta razón, afirma:

Al responder la pregunta inicial de la filosofía, Nietzsche no se limita a describir el devenir de Heráclito, sino que da una respuesta nueva, mediante la cual nomina el ser del mundo de tal manera, que ya en el acto de la nominación se sale del horizonte de los griegos. (Cruz Vélez, 1997, p. 48)

La forma expresa como Nietzsche se refiere al ser y al mundo en general es Leben [vida]. En la exégesis, el pensador colombiano hace la salvedad de que vida en este sentido no se refiere exclusivamente al ser orgánico de las plantas y animales, sino a la totalidad de los entes, sobre todo a la vida de los seres dotados de voluntad, susceptibles de querer yactuar. A diferencia de los biólogos de su época, como Spencer y Darwin, quienes definieron la vida como adaptación y conservación, Nietzsche considera la vida como voluntad de poder. De este modo,Nietzsche responde que el ser del mundo es la voluntad de poder, es decir, el ego volo y con esto queda circunscrito en la metafísica de la subjetividad cartesiana. De esta forma, lo que Descartes depositó en el ego cogito, Nietzsche lo colocó en el ego volo. En términos generales, estos son los argumentos de Cruz Vélez, que justifican la tesis de que Nietzsche, a pesar de que considere que logra superar la metafísica, termina haciendo una crítica a un tramo de la metafísica desde su propio seno. 
Son innumerables las referencias bibliográficas de los textos del pensador colombiano que justifican lo expuesto anteriormente. Sin embargo, a continuación se presentarán las referencias de Heidegger en las que expresa las ideas que defiende Cruz Vélez, para señalar, más que la influencia, la poca originalidad de este último.

El 'mundo verdadero', lo suprasensible, y el mundo aparente, lo sensible, constituyen conjuntamente aquello que se opone a la pura nada: el ente en total. Si se suprimea ambos, todo se hunde en la vacua nada. Nietzsche no puede querer decir esto, puesto que aspira superar el nihilismo en todas sus formas. Si recordamos que con su estética fisiológica quiere fundar el arte en la vida corporal, se verá que hay implícita allí una afirmación del mundo sensible, y no su supresión. Pero según se afirma literalmente en la última sección de la historia del platonismo, el 'mundo aparente' ha sido 'suprimido'. Ciertamente. Pero el mundo sensible solo es el 'mundo aparente' según la interpretación hecha por el platonismo. Solo con la supresión de este se abre el camino para afirmar lo sensible y, con él, el mundo no sensible del espíritu. (Heidegger, 2000a, p. 197)

La cita señala en principio la dinámica utilizada por Nietzsche, a juicio de Martin Heidegger, para destruir el mundo suprasensible. Esta es la mismaque presenta Danilo Cruz Vélez, como se advirtió páginas atrás. De la misma forma, hay innumerables citas que buscan corroborar la tesisde que Nietzsche queda enredado en la metafísica a la hora de buscar superarla. Veamos una:

Si la metafísica de Nietzsche no solo interpreta el ser como un valor desde el ente en el sentido de la voluntad de poder, si piensa además a la voluntad de poder como el principio de una nueva posición de valores y comprende a esta como una superacióndel nihilismo, entonces en ese querer superar se expresa el más extremo quedar enredada la metafísica en lo propio del nihilismo [...]. (Heidegger, 2000b, p. 305)

Entender a Nietzsche como un pensador que se circunscribe a la metafísica de la subjetividad, ya que postula la voluntad de poder como lo que define el ser del mundo es un asunto que Martin Heidegger aborda, de manera rigurosa, en diferentes subcapítulos de sus dos tomos. Sin embargo, de manera explícita, lo hace en "El nihilismo europeo", que es el texto más extenso del segundo volumen de Heidegger sobre Nietzsche y que se titula "La subjetividad en la interpretación nietzscheana de 
la historia”. De igual forma, en el segundo tomo, encontramos dos subcapítulos titulados "La toma de posición de Nietzsche respecto a Descartes"y“El proyecto de ser como voluntad de poder”. Quizá sean estos los textos más explícitos. Sin embargo, de manera tangencial, esta es una idea que atraviesa los dos tomos de Heidegger y con mucha frecuencia se encuentra esta tesis soportando otras ideas y, en últimas, es una especie de supuesto que está presente en todo el estudio que realiza Heidegger sobre Nietzsche. De este modo, la originalidad y rigurosidadde Danilo Cruz Vélez queda en entredicho

Uno de los argumentos presentados por Cruz Vélez, para restituirle el valor del mundo sensible, toma como base la cosmovisión de Heráclito. Sobre esta se cimientan a la vez las teoría de la voluntad de poder y la doctrina del eterno retorno, que a la postre sirven de argumento para ubicar a Nietzsche dentro de la metafísica de la subjetividad. Los nexos entre Nietzsche y Heráclito, presentados por el filósofo de la selva negra son innumerables y resultan explícitos e idénticos a los que señala el profesor colombiano.

En el subcapítulo "Las notas de la época de Zaratustra (1883-1884)",Heidegger tiene como propósito equiparar la doctrina del eterno retorno con la teoría del eterno fluir de Heráclito. Solo en este subcapítulo se pueden corroborar las tesis de Danilo Cruz Vélez respecto a la relación de Nietzsche con Heráclito, como, por ejemplo, la cercanía del filósofo clásico con el filósofo Alemán, en relación con el devenir, el cambio y el eterno fluir, así como la distancia que toma Nietzsche a la hora de introducir en el concepto de devenir la necesidad de un elemento que permanece en el cambio, algo que da consistencia, es decir, el mismo concepto griego de ser que tanto criticó Nietzsche. Estas últimas ideas de manera explícita las recrea el investigador colombiano en sus escritos, como quedó demostrado en la síntesis que se elaboró páginas atrás sobre la obra de Danilo Cruz Vélez.

De igual manera, en el subcapítulo "La posiciónmetafísica fundamental de Nietzsche”, Heidegger logra demostrar, de manera rigurosa, que Nietzsche no solo asumió el devenir de Heráclito a la hora de justificar la teoría del eterno retorno, sino que, aparte de esto, está comprometido con el concepto de ser acuñado por la tradición metafísica, el mismo propuesto por Parménides, es decir, el ser como consistencia presencia y eterno presente. 
En el subcapítulo"El conocimiento en el pensamiento fundamental de Nietzsche sobre la esencia de la verdad", Heidegger, aparte de confrontar el concepto de verdad de los Heráclito y Nietzsche, muestra que el último no logra superar la metafísica de Occidente e ir más allá de esta.

En el capítulo II del segundo tomo, en el que hace un estudio sobre el nihilismo europeo, Heidegger dedica una sección para analizar los cinco temas fundamentales de la obra de Nietzsche. Uno de esos temas es el de la voluntad de poder. Al considerar el tema del devenir en relación conel concepto de voluntad de poder, se logra ver la relación de Nietzsche con Heráclito, tal como la expone Danilo Cruz Vélez. Veamos un fragmento de los textos de Heidegger.

¿Cuáles son las posiciones fundamentales decisivas del comienzo, es decir, qué respuestas se dan a la pregunta conductora aún no desplegada acerca de que es el ente?

Una respuesta —en términos generales la de Parménides—dice: el ente es; una extraña respuesta; efectivamente, pero una respuesta muy profunda, porque con ella queda fijado al mismo tiempo y por vez primera para todos los que habrían de venir, incluso para Nietzsche, qué quiere decir 'es' y 'ser': consistencia y presencia, eterno presente. La otra respuesta-es en términos generales la de Heráclito-dice: el ente deviene;el ente es ente en el constante devenir, en el desplegarse y en el antitético destruirse. (Heidegger, 2000b, p. 215)

Entender el mundo como leben es el elemento que le permite a Nietzsche, a juicio de Cruz Vélez, tomar distanciadel concepto de mundo como mero devenir expuesto por Heráclito. El pensador colombiano lo expresa en los siguientes términos:

Uno de esto nombres del ser es leben, vida. En elaforismo582 de La voluntad de poder leemos: 'el ser para ello no tenemos otra representación que vida. Como podría algo muerto ser' y en el aforismo 581: 'ser como generalización del concepto vida (respirar), ser animado, querer, actuar, devenir'. (p. 215).

Podemos demostrar que esta parte del estudio es una traducción literal de los textos de Heidegger, sin ningún tipo de referencia. Incluso toma las mismas referencias, comentarios y aforismos tomados de La voluntad de poder. 
De acuerdo con ello, la Voluntad de poder es el carácter fundamental de la vida. 'Vida' es para Nietzsche otra palabra para decir ser. 'El 'ser' no tenemos de él otra representación más que 'vivir'. ¿Cómo puede entonces 'ser' algo muerto? (La voluntad de poder, n 582). (Heidegger, 2000a, p. 373).

Es conveniente llamar la atención acerca de la similitud entre la cita 42 y 43 . Sin importar que las traducciones sean diferentes, la parte semántica se conserva intacta:

No estamos en primer lugar 'vivos' y después tenemos un aparato llamado cuerpo, sino que vivimos (leben) en la medida en que vivimos corporalmente (leiben). Este vivir corporalmente es algo esencialmente diferente del mero estar sujeto a un organismo. La mayoría de lo que sabemos del cuerpo y del correspondiente vivircorporalmente en las ciencias naturales son comprobaciones en las que el cuerpo ha sido previamente malinterpretado como mero cuerpo físico [...] todo sentimiento es un vivir corporalmente templado de tal o cual manera, un temple de ánimo que vive corporalmente de tal o cual manera. (Heidegger, 2000a, p. 103)

Lo que subyace no es para Nietzsche el 'yo' sino el 'cuerpo': 'la creencia en el cuerpo es más fundamental que la creencia en el alma' (n. 41); y 'el fenómeno del cuerpoes el fenómeno más rico, más claro, más aprehensible’ [...]. (Heidegger, 2000b, p. 153)

El cuerpo tiene que anteponerse 'metódicamente'. Lo que cuenta es el método. Ya sabemos lo que significa: lo que cuenta es el modo de proceder en la determinación de aquello a lo que se retrotrae todo lo fijable. (Heidegger, 2000a, p. 103; Heidegger, 2000b, p. 153)

Las citas que se acaban de presentar corroboran lo presentado en el comienzo de estasección, de que el pensador colombiano aclara que Nietzsche con el término leben no se refiere exclusivamente al ser orgánico o de las plantas y animales, sino a la totalidad de los entes y sobre todo a la vida de los seres dotados de voluntad, susceptibles de querer yactuar, es decir, al mundo en general, a diferencia de Spencer y Darwin. Nietzsche a diferencia de ellos define la vida como voluntad de poder, esto es, le da una connotación de orden ontológica a la vida. De este modo, a la pregunta por el ser del ente o del mundo, este va a responder que el ser es la voluntad de poder, 
es decir, el ego volo. Con esto,se ubica en la metafísica de la subjetividad cartesiana. Deestamanera, la idea que Descartes expresó con el ego cogito, Nietzsche la entiende a partir del ego volo. Corroboremos lo dicho a partir de algunas citas más explícitas de Heidegger al respecto:

Pero ¿dónde tiene esta metafísica su fundamento histórico esencial? Preguntado de otro modo: ¿dónde tiene la idea de valor su origen 'metafísico'? Si la metafísica es la verdad sobre el ente en su totalidad y habla por tanto del ser del ente, ¿de qué interpretación del ente en su totalidad surge la idea de valor? Respondemos: de la determinación del ente en su totalidad por el carácter fundamental de la voluntad de poder. ¿Dónde surge el proyecto del ente en su totalidad que lo muestra como voluntad de poder? solo con esta pregunta pensamos en la raíz del origen de la posición de valores dentro de la metafísica. (Heidegger, 2000b, p. 98)

Podemos citar textos aún más explícitos respecto al carácter ontológico del concepto de voluntad de poder, como el siguiente:

\begin{abstract}
¿Qué sucede aquí? Nietzsche retrotrae el ego cogito a un ego volo e interprete el vellecomo querer en el sentido de la voluntad de poder, a la que piensa como el carácter fundamental del ente en su totalidad. Pero ¿qué pasaría si la instauración de este carácter fundamental solo fuera posible sobre el terreno de la posición metafísica de Descartes? [...] la siguiente proposición muestra hasta qué punto Nietzsche se encuentra ya arrojado fuera de los cauces de una meditación metafísica originaria. (p. 150)
\end{abstract}

Todo lo anterior lo podemos corroborar con los textos mismos referenciados en lasreferencias. No se quiere desconocer en ningún momento el trabajo de Danilo Cruz Vélez en temas de filosofía política, antropología filosófica, filosofía del lenguaje, etc. Sin embargo, en lo referente al tema de metafísica y nihilismo, apelando a la autoridad de los textos mismos, podemos concluir en esta sección que Danilo Cruz Vélez, lejos de elaborar un trabajo o investigación rigurosa, se limita a transcribir y traducir los estudios de Heidegger al respecto. Se le abona la claridad en el discurso y el manejo de la lengua alemana, pero, en esta parte del trabajo, no encontramos ningún paliativo que lo exima del plagio y la falta de respeto por la propiedad intelectual 


\section{Referencias}

Aristóteles. (1979). Ética nicomaquea. Bogotá: Ediciones Universales.

Cruz Vélez, D. (1970). Filosofía sin supuestos. Buenos Aires: Suramericana.

Cruz Vélez, D. (1972). Nihilismo e inmoralismo. Revista Eco, 6(153).

Cruz Vélez, D. (1997). El puesto de Nietzsche en la historia de la filosofía. En, $A$ propósito de Friedrich Nietzsche. Bogotá: Norma.

Heidegger, M. (1977). La voluntad de poder como arte. En R. Pérez Mantilla (Comp.), Nietzsche 125 años. Bogotá: Temis.

Heidegger, M. (1997). El libro de La voluntad de poder. En A propósito de Friedrich Nietzsche. Bogotá: Norma.

Heidegger, M. (2000a). Heidegger sobre Nietzsche (J. L. Bernal, Trad., Vol. 1). Barcelona: Destino.

Heidegger, M. (2000b). Heidegger sobre Nietzsche (J. L. Bernal, Trad., Vol. 2). Barcelona: Destino.

Nietzsche, F. (1968). Anticristo. Madrid: Biblioteca de Autores Cristianos.

Nietzsche, F. (1970). La gaya ciencia. Madrid: Biblioteca de Autores Cristianos.

Nietzsche, F. (1975). La voluntad de poder. Bogotá: Panamericana.

Nietzsche, F. (1994). Así hablaba Zaratustra. Bogotá: Norma.

Nietzsche, F. (1997). Fragmentos póstumos (G. Colli y M. Montari, Comp.). Bogotá: Norma.

Nietzsche, F. (1999a). Aurora. Bogotá: Esquilo.

Nietzsche, F. (2001). Ecce homo. Bogotá: Esquilo.

Platón, (1997). La República. Bogotá: Panamericana.

Whitman, W. (1981). Canto a mí mismo. Madrid: Visor Libros. 